\title{
On the assessment of the moisture transport by the Great Plains low-level jet
}

Iago Algarra ${ }^{1}$, Jorge Eiras-Barca ${ }^{1}$, Gonzalo Miguez-Macho ${ }^{2}$, Raquel Nieto ${ }^{1}$, and Luis Gimeno ${ }^{1}$

${ }^{1}$ EPhysLab (Environmental Physics Laboratory), Facultade de Ciencias, Universidade de Vigo, Ourense, Galicia, Spain

${ }^{2}$ Non-Linear Physics Group, University of Santiago de Compostela, Galicia, Spain

Correspondence to: Iago Algarra (ialgarra@uvigo.es)

Supplementary Material

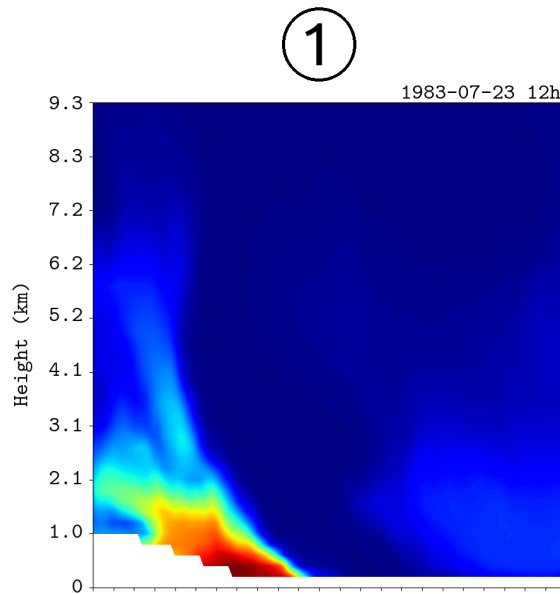

(a)

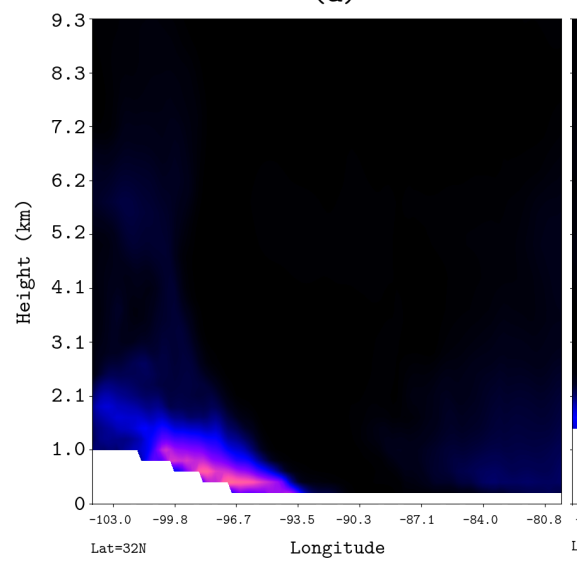

(d)
(2)

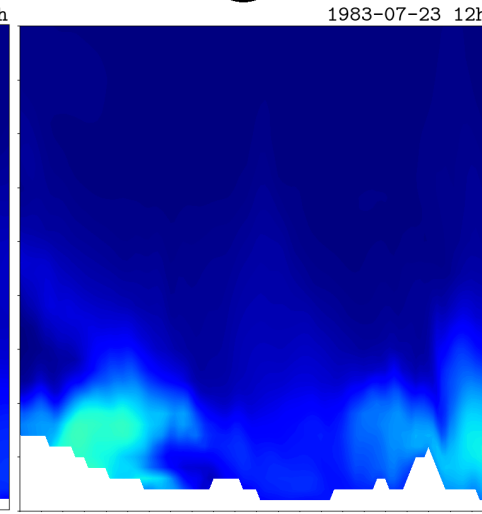

(b)

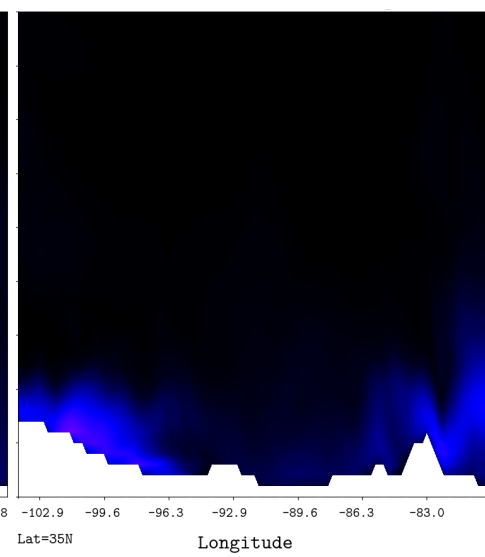

(e)
(3)

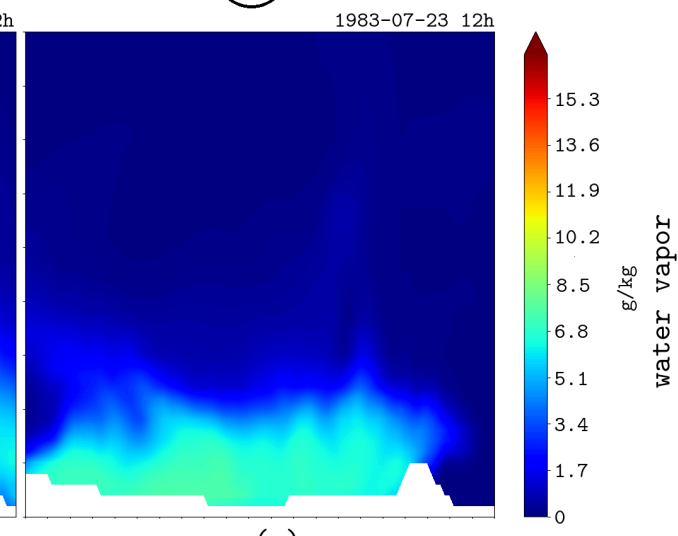

(c)

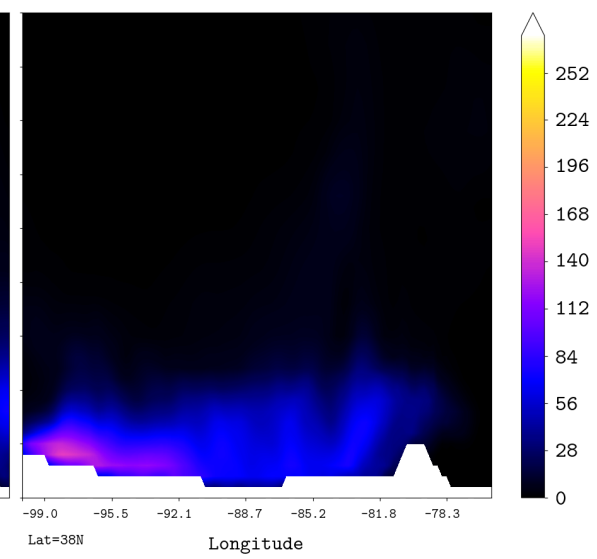

(f) 


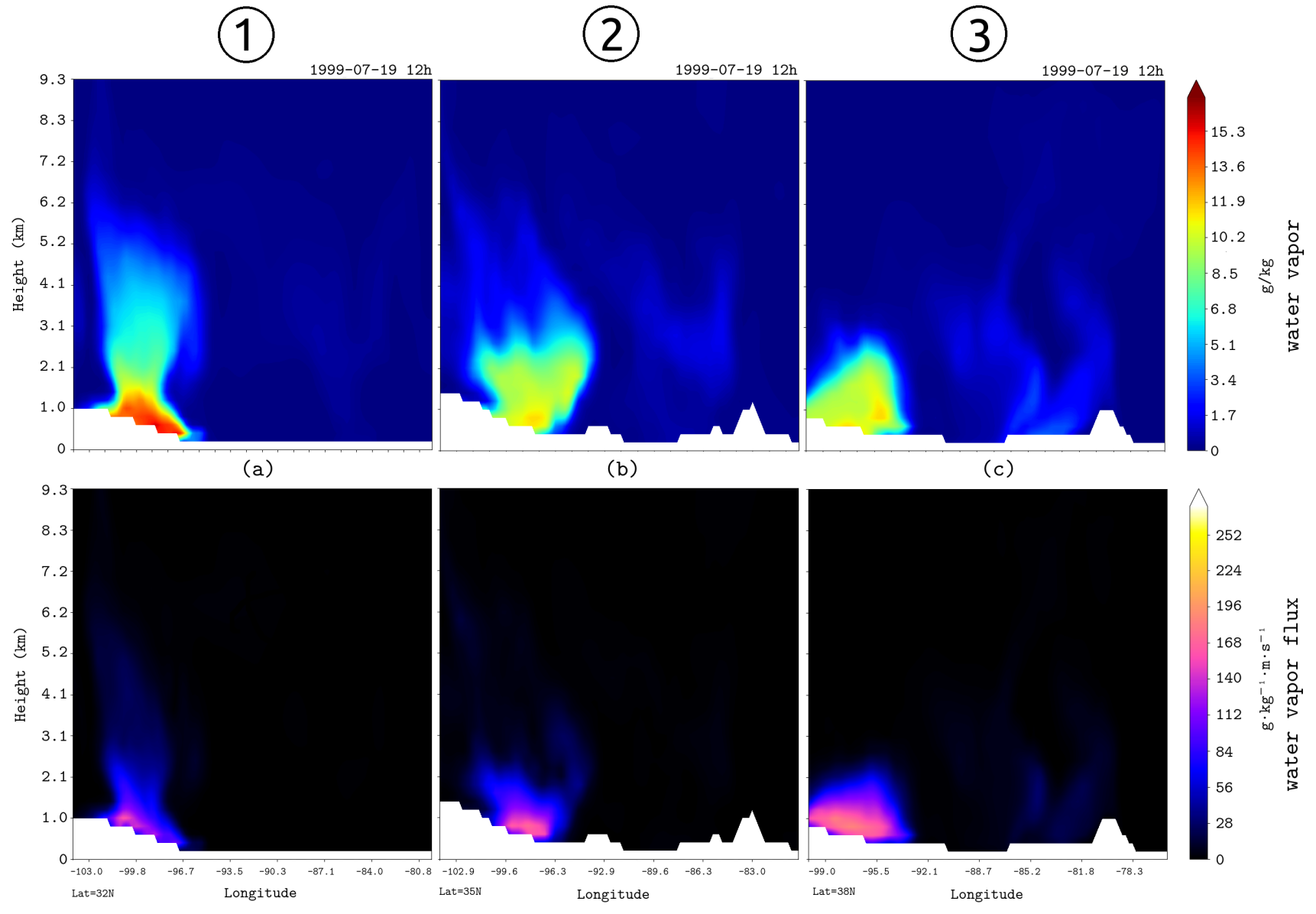

(d)

(e)

(f) 


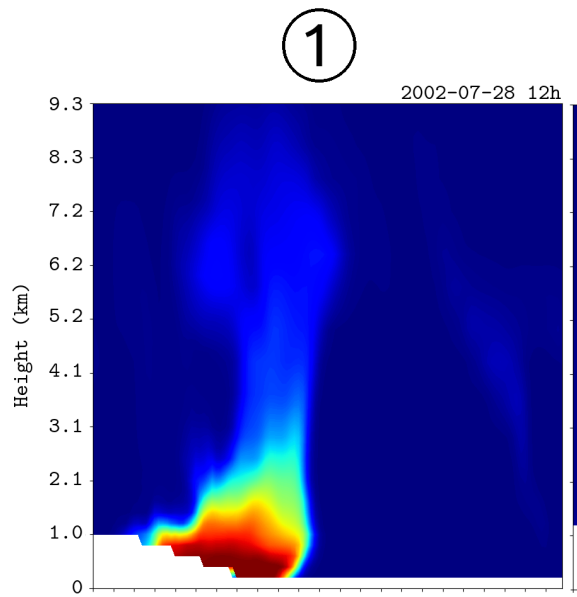

(a)

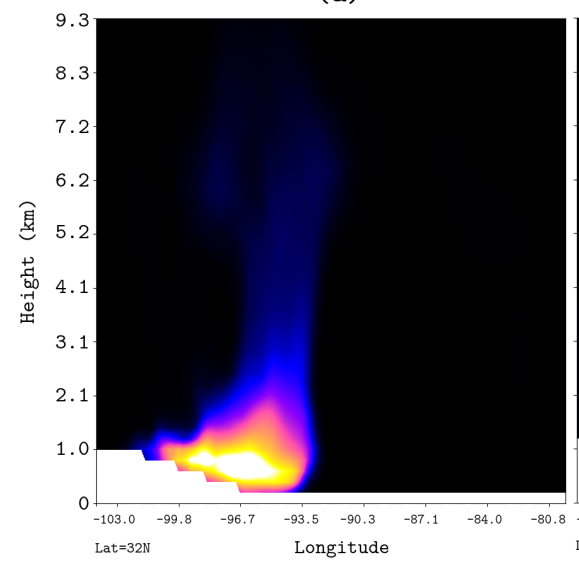

(d)
(2)

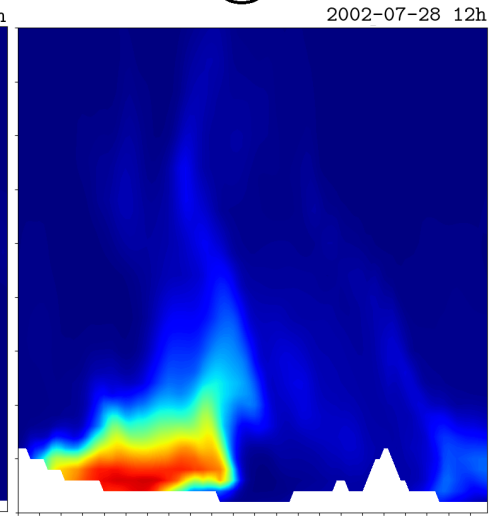

(b)

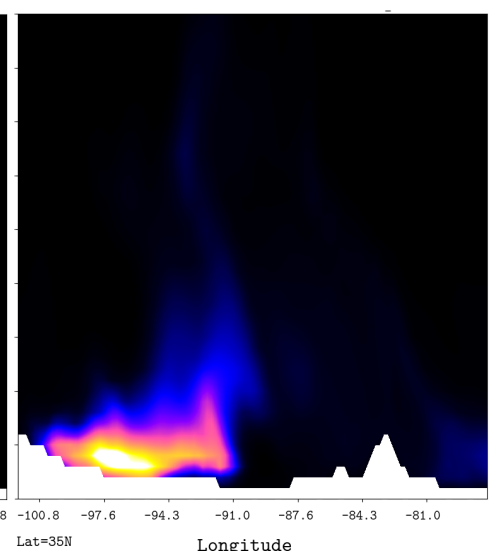

(e)
(3)

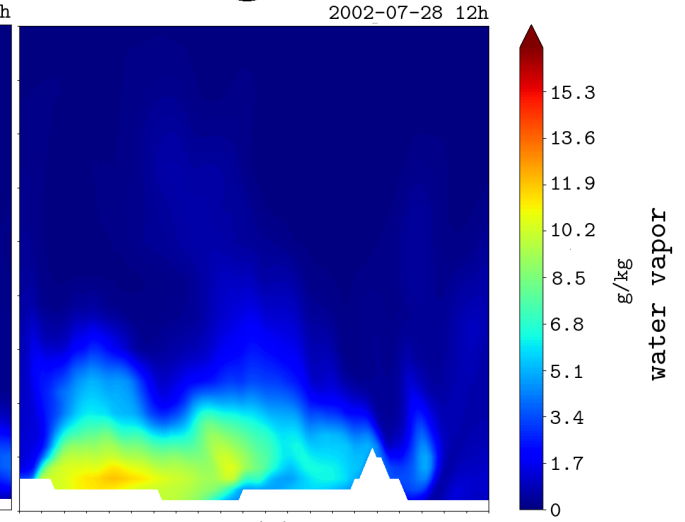

(c)

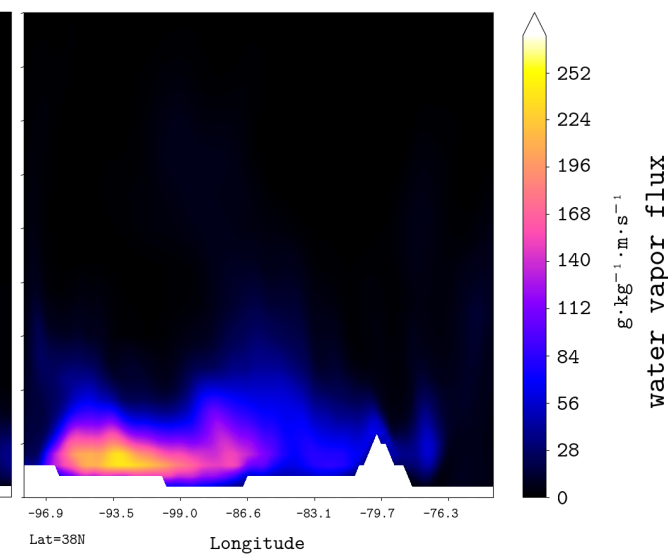

(f) 


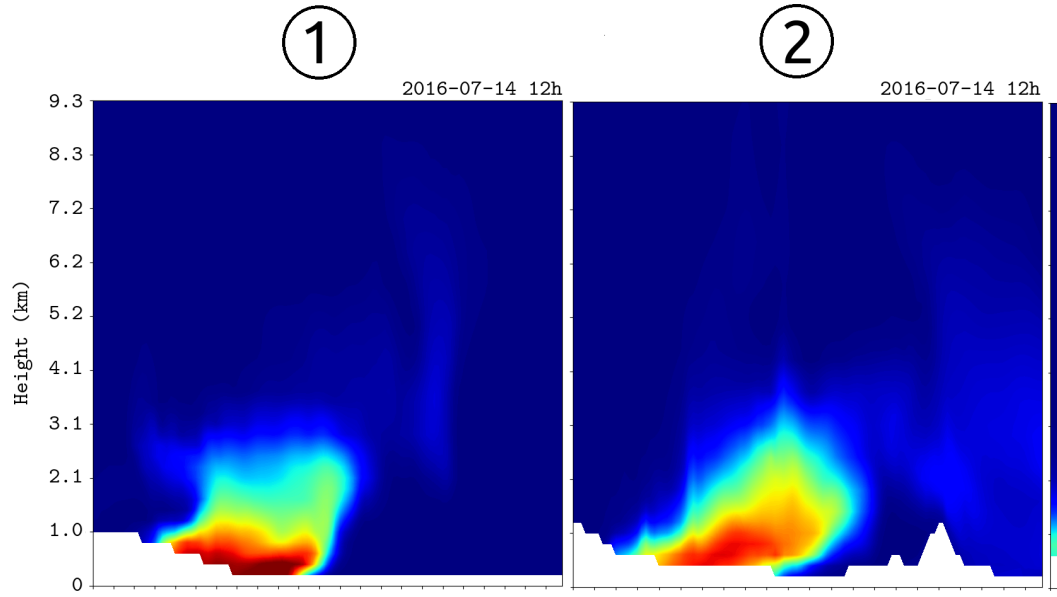

(a)

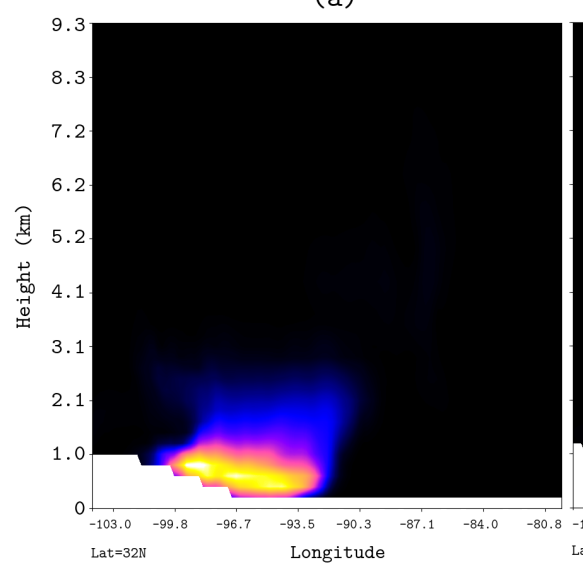

(d) (b)

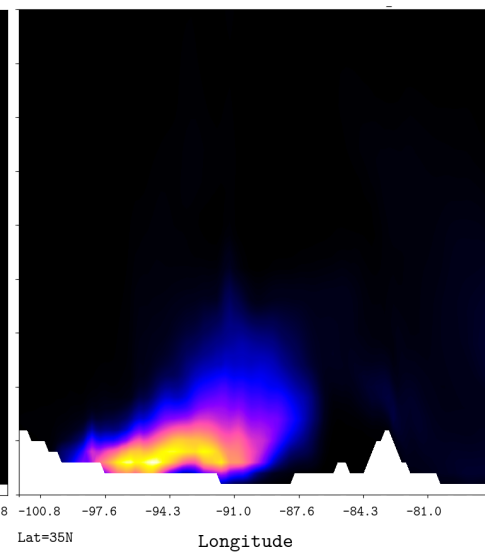

(e)
(3)

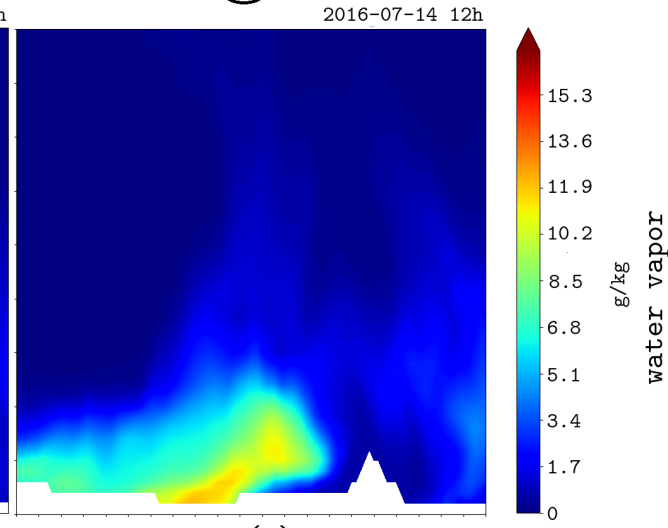

(c)

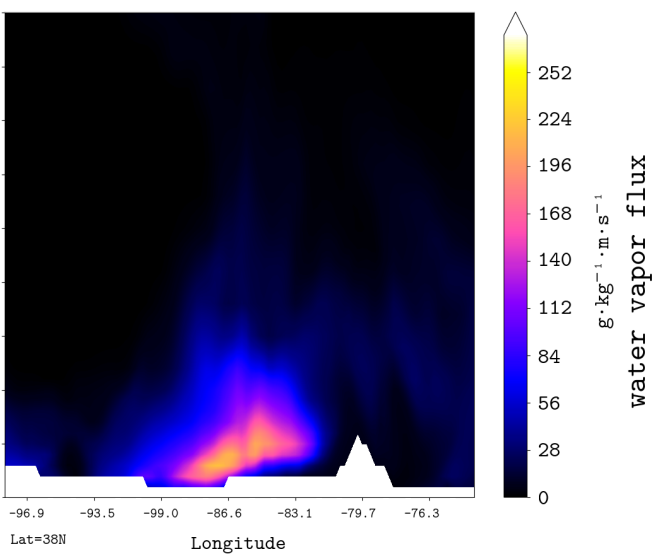

(f) 